\title{
Applied Biocatalysis with an Organic Resistant Partially Purified Lipase from $P$. aeruginosa During FAME Production
}

\author{
Jairo M. Perdomo Cabrejo, Luis E. Díaz Barrera and Rosa E. Prieto-Correa*
}

Universidad de La Sabana, Facultad de Ingeniería, Chía, Cundinamarca, Colombia

\begin{abstract}
A partially purified lipase from the Pseudomonas aeruginosa strain (PSA-01) isolated from the palm oil fruit Elaeis guineensis was used as biocatalyst to produce fatty acid methyl esters (FAME). Lyophilized lipase supernatant (LLS) was used during the first step to screen the main variables $(\mathrm{pH}$, temperature, stoichiometric oil:methanol ratio, water content and type of oil). Other variables which were identified during the screening assays (scale of reaction recipient, LLS amount and use of hexane to solubilize methanol forming a methanol-oil microemulsion) were tested during a second step. The response variable was \% molar yield of FAME. It was quantified by GC. Additionally, the LLS work parameters were optimized and compared to a partially purified lipase (PPL) during a final assay. The first-order interactions between the analyzed factors were significant $(\mathrm{p}<0.05)$. The highest yield was $4.16 \% \mathrm{w} / \mathrm{w}$ (respect to oil) using a partially purified lipase (PPL) with $\mathrm{pH} 8$, refined, bleached, and deodorized oil (RBD), 5\% water (by volume) in oil and $10 \%$ hexane (by volume), and a stoichiometric ratio of $1: 170$ oil:methanol. The final assay was carried out at $54{ }^{\circ} \mathrm{C}$ and $200 \mathrm{rpm}$ for 48 hours. It resulted in a $34.68 \%$ conversion using PPL. It also showed a 13 -fold improvement versus the initial yield with LLS, suggesting the need for a better purification process. During this research, the lipase was partially purified and used at an alkaline $\mathrm{pH}$. It showed resistance to organic compounds such as methanol and hexane. This implies great potential to act as an effective biocatalyst in the implementation of biodiesel production processes.
\end{abstract}

Keywords: Biocatalysis, lipase, $P$. aeruginosa, FAME.

\section{INTRODUCTION}

Lipases are used as biocatalyst in transesterification reaction of fatty acids to produce FAME. They are classified as triacylglycerol hydrolases (EC. 3.1.1.3) [1]; and they are associated with lipid bioconversion in living organisms to obtain a large amount of energy. Lipases are grouped in extracellular and intracellular [2]. Many microbial strains have been used to obtain lipases, but the most frequently reported enzyme sources are Candida sp., Pseudomonas $s p$. and Rhizopus sp. Lipase producer microorganisms have been studied from different sources, mainly from soil, marine water, waste water and industrial waste [3]. One of the most widely used feedstocks to produce FAME is the Palm oil from Elaeis guineensis.

In transesterification reaction, a catalyst such as an acid, a base or an enzyme, is needed to make the process faster and more profitable. Otherwise, this process would be slow and uninteresting. This process is also reversible, requiring a driving force toward the right to produce methyl esters (FAME). The most widely proposed way to overcome this imbalance is through the addition of alcohol in excess to the reaction mixture according to the principle of Le Chatelier [4]. Obtaining biodiesel from oils involves conversion of the triacyl glycerides into three molecules of fatty acid alkyl esters through a reaction with a short chain alcohol; a free

*Address correspondence to this author at the Campus del Puente del Común, Km 7, Autopista Norte de Bogotá. Chía, Cundinamarca, Colombia; Tel/ Fax: 571 8615555, Ext. 25215;

E-mail: erlide.prieto@unisabana.edu.co glycerol molecule is formed as a byproduct in a stepwise reaction [5].

Promising catalytic processes based on lipases according to the different reactions they can catalyze (hydrolysis, interesterification, transesterification) have been reported [6] Enzymes have advantages over acidic and basic catalysts: less energy consumption (room temperature reaction conditions), easier product separation, reduce treatment costs related to chemical catalyst recovery, regeneration and reuse when it is immobilized, a final product with neither alkalinity nor acidity, less water consumption and minor waste water treatment. Enzymes also guarantee that both free fatty acids and triglycerides are converted to fatty acid alkyl esters $[3,7,8]$. However, enzymatic biodiesel production has drawbacks related to actual industrial enzymes which are characterized by high production costs, inhibition by secondary products, low yields, low reaction rates, and low enzyme stability in the presence of methanol in excess [9].

Due to the long reaction time and high cost of commercial enzymes, enzymatic biodiesel production is more expensive than alkali-catalysis processes [10]. Each purification step in a enzyme production process results in a increases cost significance of catalyst. Feedstock's cost is the major economic factor for industrial biodiesel production, as approximately seventy to ninety-five percent of the total production biodiesel cost are related to raw materials (triglycerides source, alcohol, catalyst, co-solvent, etc) [11]. The purpose of this work is to evaluate a partially purified lipase from Pseudomonas aeruginosa to obtain alkyl esters, as an alternative to reduce the enzymatic production process 
cost, identifying the best transesterification process conditions to modify palm oil with methanol to obtain the higher possible yield of FAME.

\section{MATERIALS AND METHODS}

\section{Reagents and Biocatalyst}

Methanol was chosen as acyl acceptor. Short chain alcohols like methanol and ethanol are suitable for transesterification with Pseudomonas lipases. However, better yields are reported with methanol because of its small molecular weight and higher polarity, which allows a major diffusion in the reaction media [12].

$P$. aeruginosa was obtained from the palm fruits of Manuelita S.A crops in a previous work by Uscategui et al. [13]. Lipase was named as LPSA-01 according to the name of the strain. The crude palm oil (CPO) and the refined, bleached, and deodorized oil (RBD) were supplied by Del Llano S.A. The reagents were RA grade and were obtained from different suppliers.

LLS was obtained by 24-hour liquid/submerged fermentation $(\mathrm{LF} / \mathrm{SmF})$ in an enriched broth using CPO as inducer. Supernatant was filtered, concentrated and dialyzed using tangential filtration with a MILLIPORE Pellicon XL Biomax 5 cassette (MILLIPORE Labscale TFF System, USA) to remove proteins smaller than $5 \mathrm{kDa}$. Afterwards, the dialysate was lyophilized at $0.04 \mathrm{mbar},-40^{\circ} \mathrm{C}$ (Labconco Freezone 1, USA). LLS was used directly in the reaction. PPL was obtained using molecular exclusion chromatography with BIO-RAD Bio-gel P-60 (BIO-RAD BioLogic LP system, USA) following the manufacturer protocol to obtain a fraction containing a partially purified lipase (PPL). Protein quantification by modified Bradford assay [14], catalytic activity by p-nitrophenol liberation [15] and electrophoresis were carried out during each purification step (data not shown).

\section{First Assay-LLS}

Standard reaction conditions were established by a factorial experiment design using Analysis of Variance (ANOVA and Response Surface Methodologies (RSM) in JMP 10.0.0 software (SAS Institute Inc). Transesterification experiment was carried out in $100 \mathrm{ml}$ erlenmeyers in an incubator-shaker (JEIO IS-971, Korea) during 48 hours at $200 \mathrm{rpm}$. CPO or RBD oil was loaded first on each flask. Then methanol and lipase at defined $\mathrm{pH}$ (buffer) were loaded according to the factorial design. A final sample of each treatment was treated with hexane and FAME concentration was obtained by Gas Chromatography (GC, Agilent Technologies 7890A GC System, CA USA. HP88 column, FID, flow: $1 \mathrm{~mL} / \mathrm{min}$, and argon as carry gas). The response variable in all experiments was \% FAME yield, calculated using Eq. 1.

$$
\text { FAME yield }(\%)=D F \times \frac{M_{F A M E}}{M_{\text {Used oil }}} \times 100 \%
$$

Equation 1. Porcentual conversion of oil to methyl esters.

DF is dilution factor, $\mathrm{M}_{\mathrm{FAME}}$ is mols of FAME, and $\mathrm{M}_{\text {used }}$ oil is initial mols of CPO or RBD oil in the reaction mixture.
First assay was a $2^{5}$ full factorial design with 32 experimental units. Coded variables are provided in Table $\mathbf{1}$.

Table 1. Coded variables for first assay.

\begin{tabular}{|l|c|c|}
\hline Variable & -1 & +1 \\
\hline Temperature $\left({ }^{\circ} \mathbf{C}\right)$ & 42 & 58 \\
\hline $\mathbf{p H}$ & 6 & 8 \\
\hline Oil & Crude (CPO) & Refined (RBD) \\
\hline $\begin{array}{l}\text { Oil:methanol (volume) } \\
\text { (Stoichiometric relation) }\end{array}$ & $\begin{array}{c}1: 4 \\
(1: 100)\end{array}$ & $\begin{array}{c}1: 6 \\
(1: 149)\end{array}$ \\
\hline Water amount (\%V/V water-oil) & 10 & 30 \\
\hline
\end{tabular}

\section{Collateral Assays}

These assays were carried out to analyze secondary variables such as scale of reaction, lipase concentration and addition of co-solvent, which were identified during first assay. These variables were combined with the first assay variables at different levels using full factorial designs. Reaction was carried out at $42^{\circ} \mathrm{C}$ for 48 hours at $200 \mathrm{rpm}$. Experimental design variables and levels are summarized in Table 2.

Table 2. Variables and levels for collateral assays (first and third assays were carried out with 2 replicates and the second assay was carried with 1 replicate).

\begin{tabular}{|c|c|c|c|}
\hline Assay & Variables & Levels & Variable Code \\
\hline \multirow{4}{*}{1} & \multirow{2}{*}{ Vessel scale (ml) } & 10 & -1 \\
\hline & & 100 & 1 \\
\hline & \multirow{2}{*}{$\begin{array}{l}\text { Stoichiometric } \\
\text { relation oil-methanol }\end{array}$} & $1: 6$ & -1 \\
\hline & & $1: 140$ & 1 \\
\hline \multirow{6}{*}{2} & \multirow{3}{*}{$\begin{array}{l}\text { Catalyst amount } \\
(\mathrm{mg} / \mathrm{ml})\end{array}$} & $20(1.35 \% \mathrm{w})$ & -1 \\
\hline & & $80(5.39 \% \mathrm{w})$ & 0 \\
\hline & & $140(9.44 \% \mathrm{w})$ & 1 \\
\hline & \multirow{3}{*}{$\begin{array}{l}\text { Stoichiometric } \\
\text { relation oil-methanol }\end{array}$} & $1: 56$ & -1 \\
\hline & & $1: 106$ & 0 \\
\hline & & $1: 156$ & 1 \\
\hline \multirow{6}{*}{3} & \multirow{2}{*}{$\begin{array}{l}\text { Sotoichiometric } \\
\text { relation oil-methanol }\end{array}$} & $1: 6$ & -1 \\
\hline & & $1: 156$ & 1 \\
\hline & \multirow{2}{*}{ Cosolvent } & No cosolvent & -1 \\
\hline & & Hexane-oil (v/v) 1:1 & 1 \\
\hline & \multirow{2}{*}{ Water } & $2 \%$ & -1 \\
\hline & & $10 \%$ & 1 \\
\hline
\end{tabular}

\section{Final Assay}

A $2 \mathrm{~V}^{5-1}$ fractional factorial with 5 central points and 21 experimental units was carried out, as described by Gutiérrez [16]. Response surface was used to identify the most significant variables for improving FAME production. The model equation used to perform this analysis is shown in Eq. 2 


$$
Y=\beta_{k 0}+\sum_{i=1}^{5} \beta_{k i} X_{i}+\sum_{i=1}^{4} \sum_{j=i+1}^{5} \beta_{k i j} X_{i} X_{j}
$$

Equation 2. Model used for response surface process improvement.

In this model, $Y$ is the response variable (\%Yield), $\mathrm{B}_{\mathrm{k} 0}$, $\mathrm{B}_{\mathrm{ki}}, \mathrm{B}_{\mathrm{kij}}$, are constants (estimated parameters), $\mathrm{X}_{\mathrm{i}}$ and $\mathrm{X}_{\mathrm{j}}$ are independent decoded variables. The central points included a $7.5 \%$ water content, a $20 \%$ co-solvent content, a 1:156 oil: methanol stoichiometry, $\mathrm{pH} \mathrm{10}$, and without lipase. The idea was to evaluate any individual first order $\mathrm{pH}$ effect due to a high buffer $\mathrm{pH}$. Fixed variables were RBD oil, 4.16\% catalyst (due to the availability of the PPL), and a temperature of $54^{\circ} \mathrm{C}$ (determined on a parallel work assay, data not shown). All assays proceeded for 48 hours at 200 rpm.

\section{RESULTS}

\section{First Assay}

Data analysis (JMP 10.0 software) of the first LLS assay using SLS $\left(\mathrm{R}^{2}=0.8213 ; \alpha=0.05\right)$ showed significant individual effect $(\mathrm{P}<0.0001)$ for $\mathrm{pH}$, oil, water and stoichiometric ratio. Temperature was not significant $(\mathrm{P}=0.3500)$, but it presents a first order interaction with oil (Fig. 1). Moreover, $\mathrm{pH}$ showed a first order interaction with oil, obtaining better results with RBD oil at $\mathrm{pH} 8$. The highest response was obtained with $\mathrm{pH} 8$, RBD oil, $42^{\circ} \mathrm{C}$, stoichiometric relation oil:methanol $1: 149$ and $10 \%$ $\mathrm{v} / \mathrm{v}$ water: oil. The mean response in this assay was $2.41 \%$ FAME conversion yield.

According to reviewed literature [17, 18], a minimum amount of water is required to guarantee lipase activity and this quantity is unique for each lipase. This point will be discussed later in this work.

\section{Collateral Assays}

The best results were reached when reaction was carried out in small scale vessels $(10-\mathrm{mL}$ vials instead of $100-\mathrm{mL}$
Erlenmeyer flasks), due to the fact that small reaction volumes propitiate more collisions between reactive. In addition, increasing the amount of lipase up to $9.44 \%$ lipaseoil in the reaction resulted in a significant yield improvement (highest concentration tested due to the availability of the lipase, Fig. 2).

The lipase was effective up to oil-methanol stoichiometric relations approximately $1: 156$ despite widely recommended stoichiometry 1:6 mols of methanol per oil mol. Higher stoichiometric relations showed a decreased FAME production (Fig. 2). The water content was reduced from $10 \%$ to $2 \% \mathrm{v} / \mathrm{v}$ of oil $(3.11 \%$ and 2.71 mean yield response, respectively), increasing the amount of FAME obtained in the first assay. Additionally, co-solvents helped to homogenize the mixture by forming a microemulsion with reverse micelles, facilitating interactions between the reagents. When a co-solvent was added (relation 1:1 volume hexane-oil) to the reaction with the lowest water content $(2 \%)$, a positive interaction occurred between these two variables $(2.81 \%$ and $2.23 \%$, to $2 \%$ and $10 \%$ of water amount respectively).

Under these conditions, the assay molar mean yield was improved from $2.41 \%$ to $3.98 \%$ FAME molar mean yield. The levels of each variable that showed the best response were chosen for the final assay (a $10 \mathrm{ml}$ vessel scale, stoichiometric relation 1:156, use of solvent and less amount of water), except catalyst concentration, due the availability of PPL.

\section{Final Assay}

RSM using $2 \mathrm{v}^{5-1}$ fractional factorial with 5 central points design was used to determine the optimal levels of the five significant factors identified in the previous assays. The coded levels for each factor are shown in Table 2. The effects of the analyzed factors and the first order interactions were predicted by the second-order polynomial function obtained on the regression analysis.
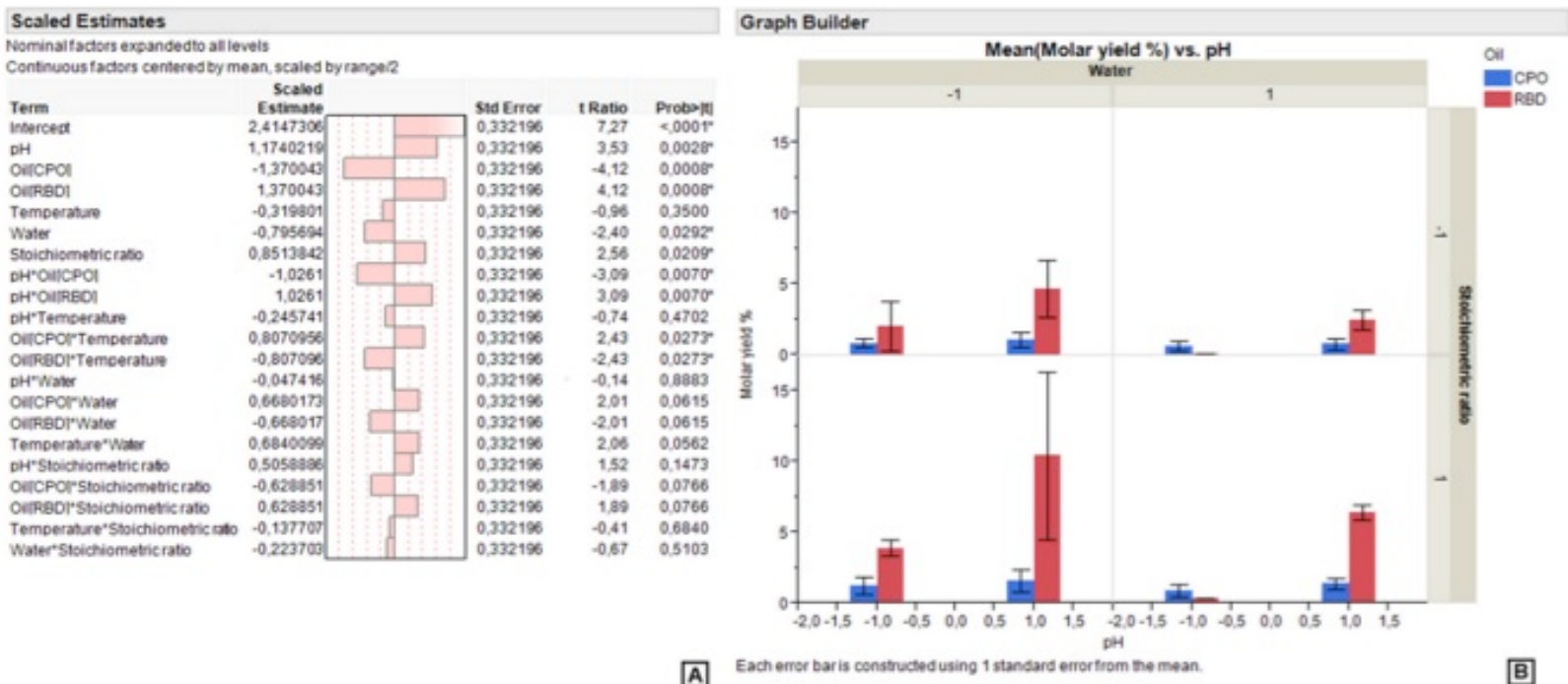

Fig. (1). A) Effects test report for the first assay analyzed factors and first order interactions. B) Interaction plot of significant individual effect variables. 

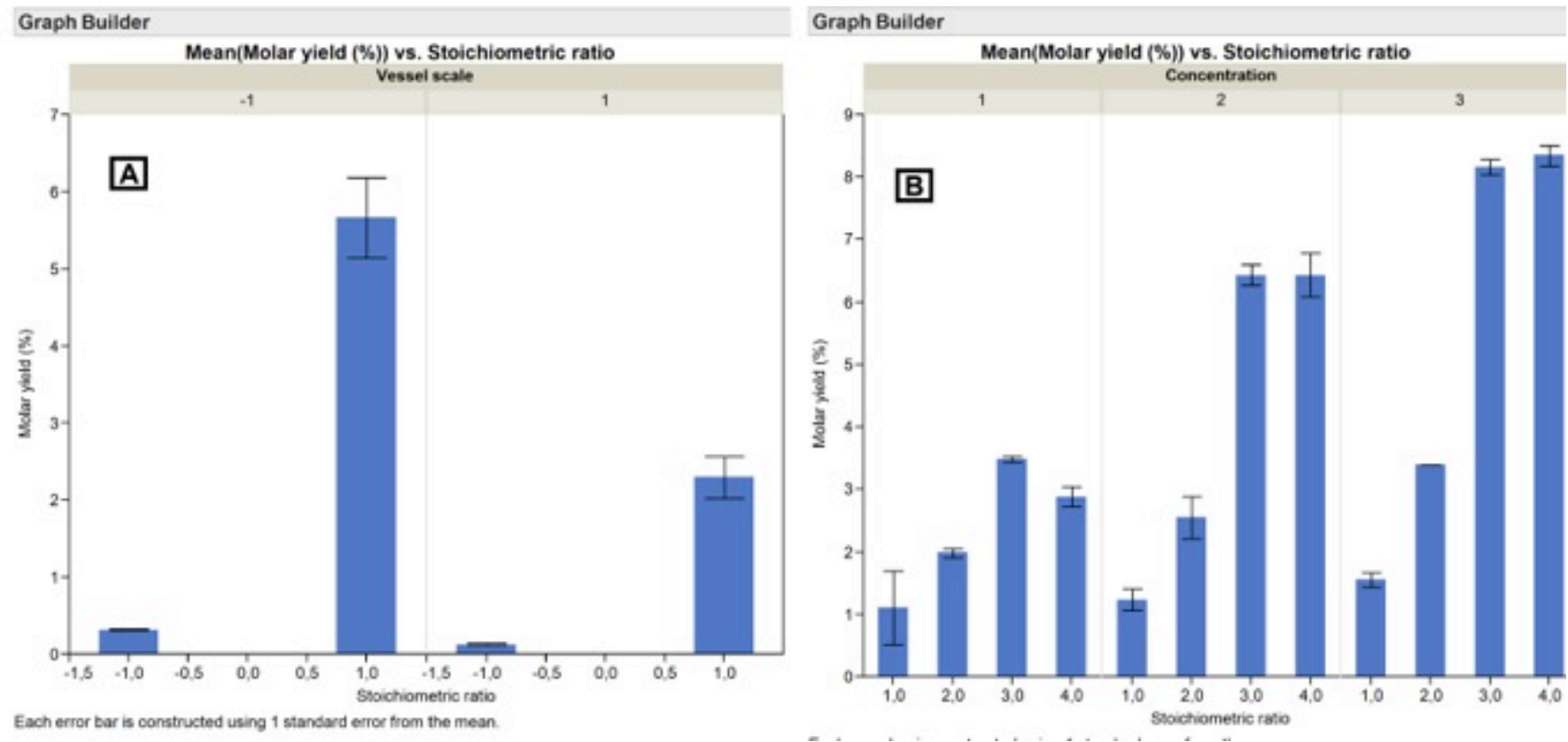

Fig. (2). A) Molar yield with two reaction scales (10 and $100 \mathrm{ml},-1$ and 1 respectively) and 1:6 and 1:156 oil/methanol molar ratios. B) Reaction yields at different biocatalyst concentrations (20,80 and $140 \mathrm{mg}$ of LLS/ml, coded variables 1,2 and 3) and stoichiometric ratios (1:56, 1:106, 1:156 and 1:206 stoichiometric ratios, coded 1, 2, 3 and 4).

$$
\begin{aligned}
\text { Molar Yield }(\%) & =35.1145+(-8.6901 * \mathrm{~A})+(-22.31 \\
& * \mathrm{~B})+(-15.177 * \mathrm{C})+(-7.5756 * \mathrm{D}) \\
& +19.4842 * \mathrm{E}+\mathrm{A} *(\mathrm{~A} * 9.6362)+\mathrm{A} \\
& *(\mathrm{~B} * 11.9214)+A *(C * 9.326)+B \\
& *(C * 10.9045)+A *(D * 7.6225+B \\
& *(D * 10.4091)+C *(D * 19.5154)+A \\
& *(E *(-20.2376))+B *(E \\
& *(-16.2933))+C *(E *(-7.2036)) \\
& +D *(E *(-9.5453))
\end{aligned}
$$

In the function, factor $\mathrm{A}$ is catalyst (coded variable, Table 2), $\mathrm{B}$ is the \% water added, $\mathrm{C}$ is $\%$ of co-solvent, $\mathrm{D}$ is alcohol mols of the oil-methanol molar ratio, and $\mathrm{E}$ is $\mathrm{pH}$ of the buffer added to carry out the biocatalyst. The statistical significance of the response surface regression model was checked by $F$ test and ANOVA (Fig. 3). The analysis showed that the second order polynomial model with the significant variables $(\mathrm{P}<0.05)$ is adjusted to the experimental data (Adjusted $\mathrm{R}^{2}=0.9602$ ). It explains $96 \%$ of the variability in the response of the assay (Molar yield $(\%)$ ).

Once the work parameters were determined, they were tested and adjusted to compare the LLS against PPL (coded variables -1 and 1 , respectively). In this assay, all the first order interactions between the variables were significant. The most important individual effect was water content, while the most significant interaction of first order was catalyst $/ \mathrm{pH}$. The response surface of this interaction showed the best response with LLS at pH 10 (Fig. 4A).

The interaction between water content and catalyst shows that reducing the water content increases the yield of FAMEs for both LLS and PPL (Fig. 4B).
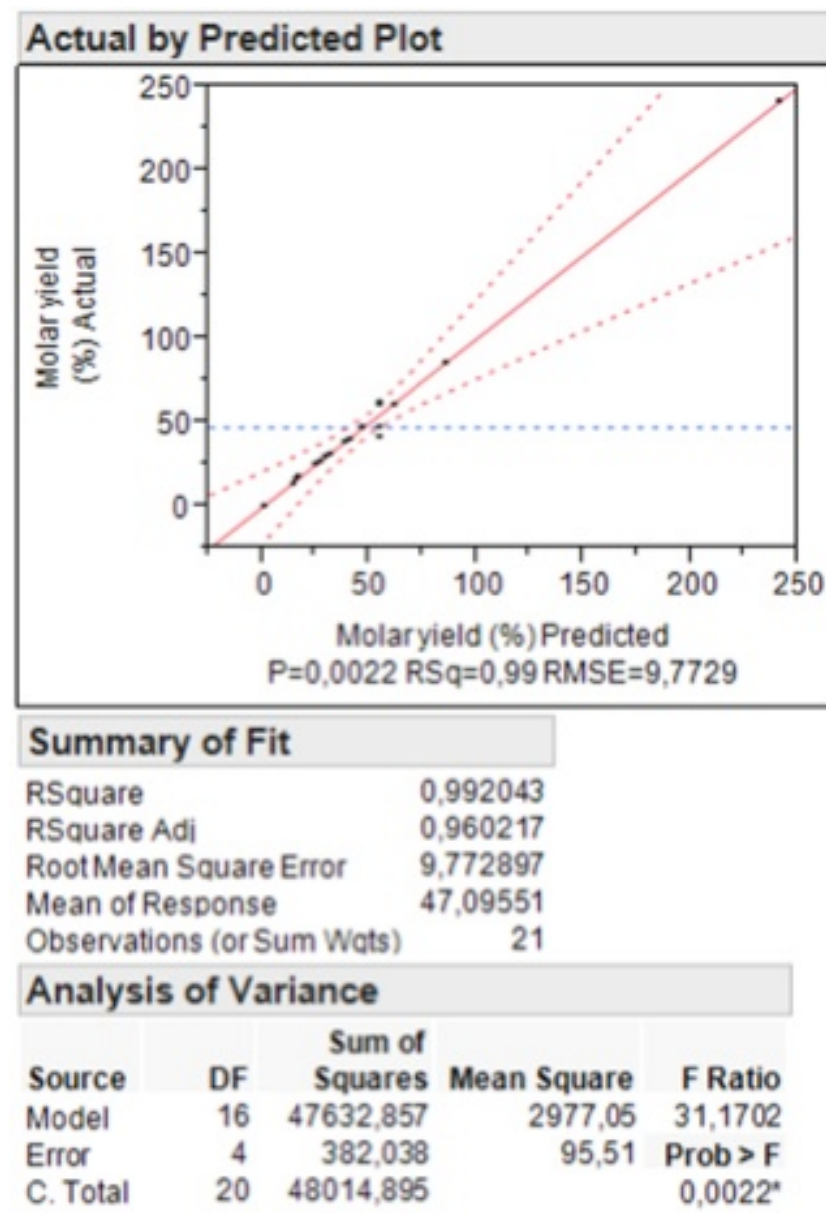

Fig. (3). Outcoming ANOVA report (JMP 10.0) for the second order polynomial model for FAME molar yield (\%). 




Fig. (4). Response surface for FAME molar yield (\%) by LLS and PPL (coded variables -1 and 1 respectively) and interactions between each catalyst with: A) $\mathrm{pH}, \mathbf{B})$ water, C) co-solvent and D) stoichiometric ratio.

The response surface between the co-solvent/catalyst showed that reducing the co-solvent content caused an increased yield, showing the highest response with LLS (Fig. 4C).

The interaction between the stoichiometric ratio and the catalyst implies an increased response for the LLS when decreasing the stoichiometric ratio. PPL remained unaffected (Fig. 4D).

Nevertheless, to avoid any possible influence by atypical data points as described by Gutiérrez [16], we analyzed the catalyst interactions using the median instead of the mean. The best response was found with PPL at $\mathrm{pH} 8$ (35.5\%, Fig. 5A). Additionally, we found that $\mathrm{pH} 10$ has a negative individual effect with a higher impact on LLS (Fig. 5A). Gao et al. [19] explains that this effect is undesirable because the typical alkali transesterification is promoted by high $\mathrm{pH}$, avoiding the biocatalysis.

The median analysis showed that increasing the stoichiometric ratio from 1:140 to 1:170 with LLS increased FAME yield $(15.77 \%$ and $25.29 \%$ respectively). PPL presented the highest molar yield and remained unaffected by the increase of stoichiometric ratio $(31.83 \%$ and $33.34 \%$ respectively, Fig. 5B). This behavior was also observed for PPL during the interaction between the co-solvent and biocatalyst (Fig. 5C), indicating that PPL could be resistant to organic solvents, such as methanol and hexane.

The interaction between the stoichiometric ratio and cosolvent shows that reducing the hexane content to $10 \%$ versus oil with a stoichiometric ratio of 1:140 promotes higher FAME production (Fig. 6A). 



Each errer bar is construcled using 1 standand enrorfrom the mean
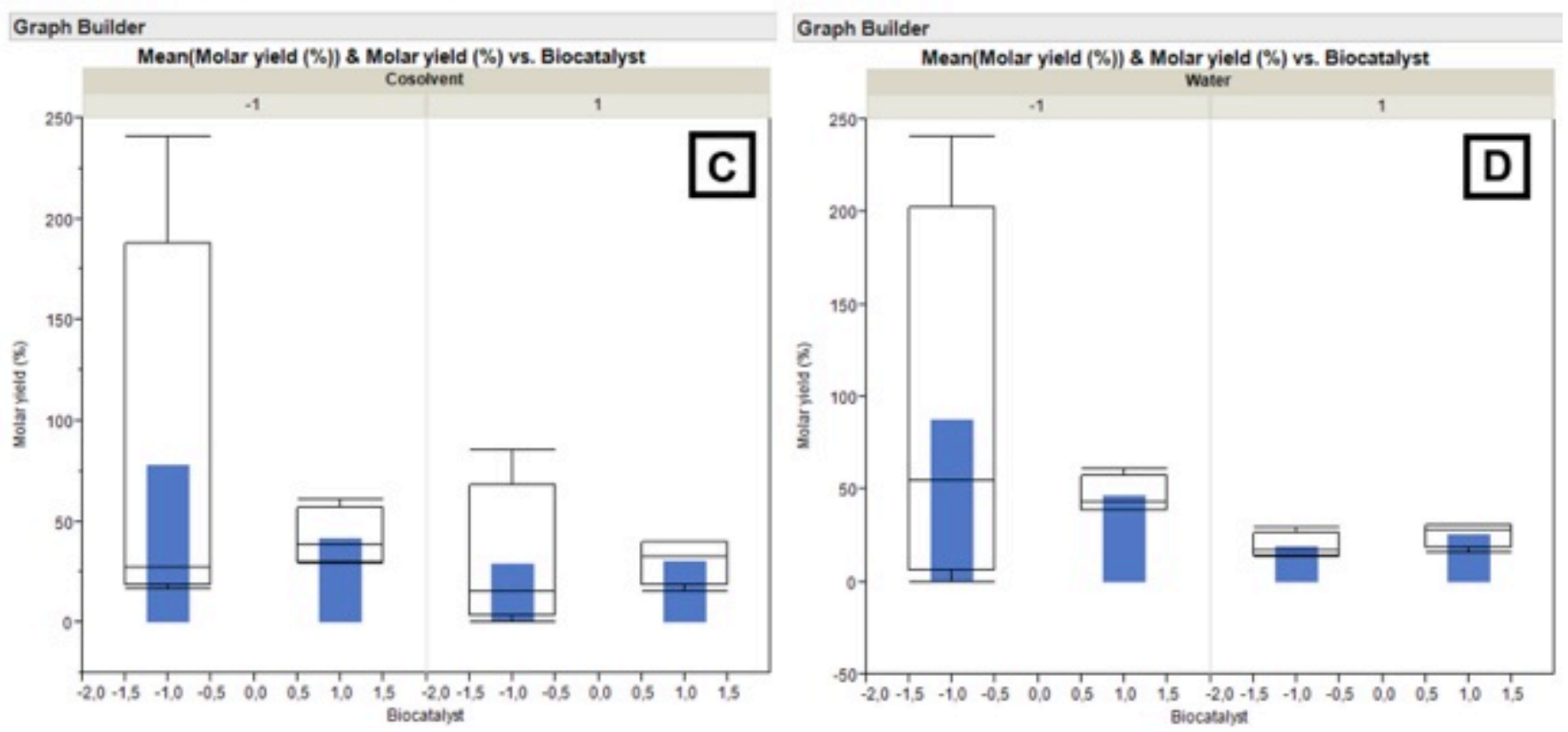

Fig. (5). Bars and boxplots for the catalyst interactions with: $\mathbf{A}) \mathrm{pH}, \mathbf{B}$ ) stoichiometric ratio, C) co-solvent, and D) amount of water.

The interaction between co-solvent and water amount showed the best response when the amount of water and cosolvent was decreased ( $5 \%$ and $10 \%$, respectively, Fig. 6B). Stoichiometric ratio and water content interaction showed an increase of FAME production after reducing the value of both variables. The best results were achieved with a 1:140 stoichiometric ratio and 5\% water content (Fig. 6C). Otherwise, the interaction between stoichiometric relation and $\mathrm{pH}$ showed an increased response with $\mathrm{pH} 10$. However, the molar yield increased with lower stoichiometric ratio (1:140, Fig. 6D).

Finally, the best response was achieved with PPL and 5\% of water, $10 \%$ of hexane, stoichiometric relation oilmethanol 1:140 and $\mathrm{pH} 10$.

The median analysis showed a deviation caused by atypical data. As a result, PPL showed a higher response than LLS (Fig. 5). PPL data were more homogeneous, and the partial purification process improved FAMEs yield during lipase biocatalysis. LLS average performance was improved by approximately 8 -fold, from $2.41 \%$ to $20.61 \%$ FAMEs molar yield. On the other hand, PPL exhibited the highest response with $34.68 \%$ FAMEs molar yield. Therefore, a minimum purification step is desirable for a more efficient process and for future industrial scaling.

\section{DISCUSSION}

Surface response methodology has proved suitable for optimizing processes that involve numerous variables. This methodology analyzes first order interactions and enables the combination of the best levels of each variable [16]. Previous research on transesterification conducted by Gao et al. [19], 


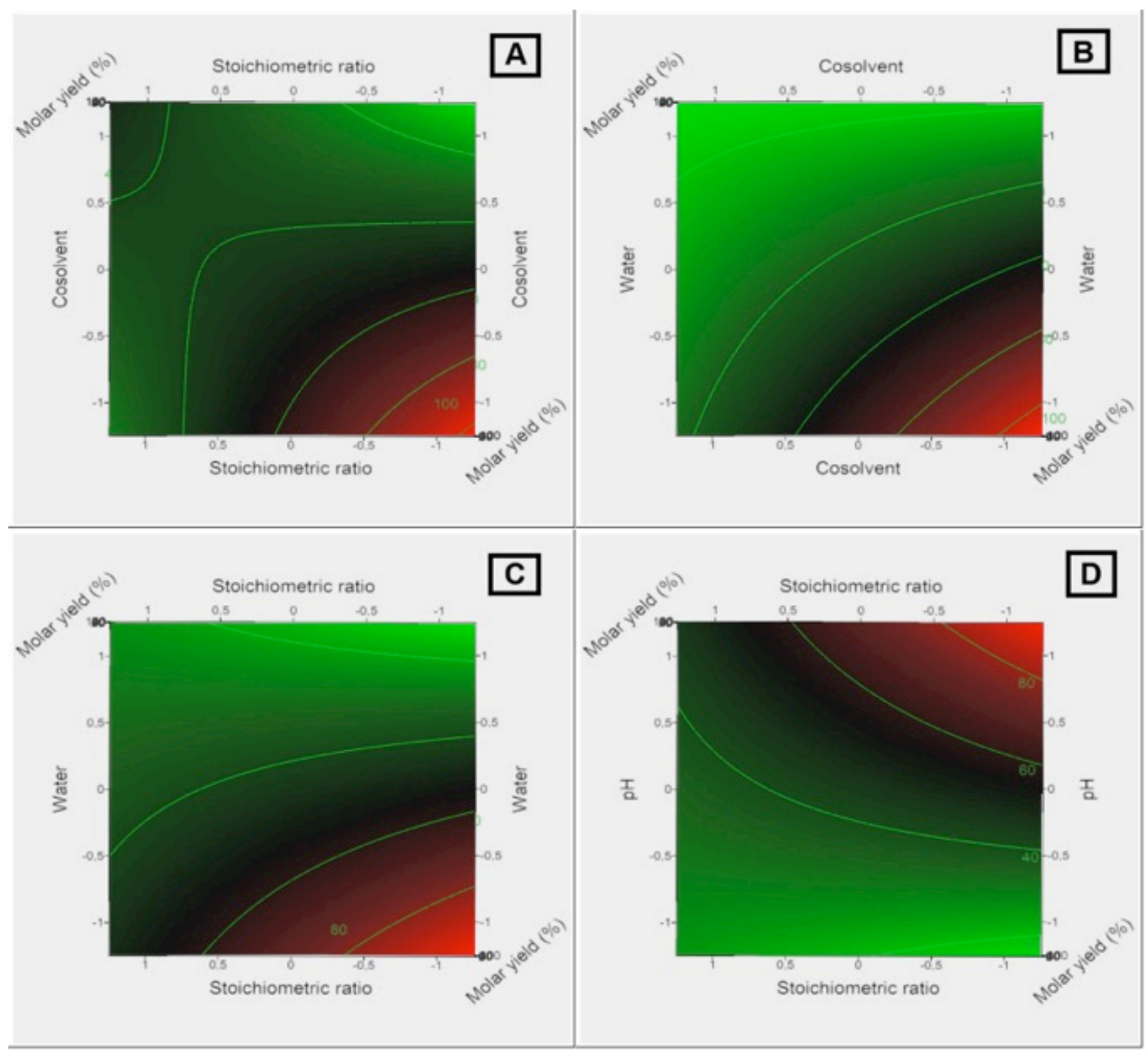

Fig. (6). Response surface plots. A) Stoichiometric ratio and co-solvent. B) Water amount and co-solvent. C) Water amount and stoichiometric ratio. D) $\mathrm{pH}$ and stoichiometric ratio.

Rodrigues [20], Shie et al. [21] and Sim et al. [22], with different kinds of catalysts showed excellent results using this methodology. However, possible mean deviations due to atypical data points have not been analyzed yet. When data are uniformly distributed, mean and median may be near each other [14]. When atypical points appear, median analysis avoid deviations and is more reliable than mean, evidencing a real data tendency. In this work, an atypical observation was identified giving a mean slant in the response surface analysis for biocatalyst interactions plots, due to the fact that biocatalyst was a nominal variable. However, this slant does not affect the numerical variables.

According to the reaction media, lipases can catalyze reactions such as hydrolysis, inter-esterification and alcoholysis. The enzyme activity changes depending on the amount of water or solvent in the surroundings of the protein. In non-aqueous media, the water amount has strong influence on the stability and catalytic activity of any lipase. Consequently, some amount of water is required to retain its activity in organic solvents, but an excess of water might influence the equilibrium in a transesterification reaction towards hydrolysis. Lipases act at the organic/aqueous interface, and water helps to increase the available interfacial area. In addition, water helps to keep hydrogen bonds and sulfide interactions, aiding in the folding of the protein. As a result, water enhances lipase activity. Therefore, to maximize the enzyme activity, the optimum water content required must be determined. However, the water amount for a certain reaction is dependent on the nature of feedstock, the lipase, the immobilized support and the organic solvent used [23]. 
In addition, each lipase attains the highest catalytic activity only at its specific temperature and $\mathrm{pH}$ due to structural properties from different sources lipases. This might be the reason for showing different activity on different oil substrates. Thus, there is a need for optimizing the process [24].

Previously reported conditions related to the same type of $P$. aeruginosa lipases were similar to results shown in this research. Best responses were achieved at alkaline $\mathrm{pH}$ and temperatures within $20^{\circ} \mathrm{C}-70^{\circ} \mathrm{C}$, which are proper for mesophilic lipases catalysis [25]. However, the highest reaction temperature in the first assay $\left(58^{\circ} \mathrm{C}\right)$ was near the boiling point of methanol $\left(64.7^{\circ} \mathrm{C}\right)$, increasing the possibility of biocatalyst denaturation after long periods, due to the high energy of the reaction system [26].

Temperature does not exert an individual effect and has similarity to the behavior trend of different mesophilic lipases reported [25]. This fact confirms that used PPL from $P$. aeruginosa is mesophilic and then, the equilibrium conversion for enzymatic biodiesel production will not be significativelly influenced within the available temperature range. Additionally, an increase of temperature enhances the reaction rate, but too high temperature will decrease the enzyme stability. Besides, low temperature and long time reaction yields are comparable to high temperature and fast reactions [5]. Consequently, interaction between the operational stability of the lipase and the reaction rate of transesterification is a key factor to determine the optimum temperature for enzymatic transesterification [12].

In the final assay, the highest yield was achieved at $54^{\circ} \mathrm{C}$ after 48 hours, remaining within the working range reported for this type of lipase on Brenda database [27]. In addition, the most efficient lipases produce conversions higher than $90 \%$ at temperatures between $30^{\circ} \mathrm{C}$ and $50^{\circ} \mathrm{C}$. Reported reaction times varied from 8 hours for immobilized enzymes to 90 hours for the same free enzymes, depending on the feedstock and alcohol [25]. Moreover, temperature of $55^{\circ} \mathrm{C}$ as the working temperature for lipases from $P$. aeruginosa has been reported $[28,29]$. This temperature showed, for all the cases, the best balance between stability and reaction rate. As result, the highest quantity of FAME was obtained in a constant time of reaction using the whole potential of the enzyme as biocatalyst.

The interaction between the oil: methanol ratio/type of oil in the first assay showed the best behavior with the highest methanol content and RBD oil. The purity of the triacyl glycerides influenced the reaction because the phospholipids in the crude oils add to the lipase surface, blocking the active site and causing inhibition. Thus, it was necessary to eliminate phospholipids by additional process to avoid mass transfer problems and improve the reaction yield $[22,30,31]$.

This research shows that the lipase is effective under high methanol concentrations. The best conversion during first assay was achieved with a stoichiometric ratio of 1:149 oil: methanol, revealing an unusual behavior. In addition, oilmethanol molar ratio in the final assay was 1:170 for LLS and PPL (median analysis). These ratios are desirable for industrial lipases because they enable the reuse and cost reduction, as proposed by some authors $[6,17,32,33]$.
However, it has drawbacks related to the high costs of the required alcohol. This issue must be carefully analyzed depending on the final use of the enzyme.

The stoichiometric ratio is a crucial variable in transesterification reactions. A lack or excess of alcohol may cause incomplete reactions or inhibit the enzyme. The average recommended stoichiometric ratio is $1: 6$, including a 3 mol excess of methanol to ensure complete reaction without lipase inhibition due to the fact that catalytic sites are occupied by the insolubilized short chain alcohol molecules $[5,32]$. This ratio varies based on the resistance of the lipase (4 to 18 alcohol/oil mol), where the high values represent high resistant lipases as reported by Ana et al. [34] and Stamenkovic et al. [35]. Another way to enhance the reaction towards FAME production is through a continuous products removal [3]. However, it needs a different experimental assembly (a continuous reaction equipment instead batch reactors).

An enzyme low molecular weight may be attributed to the increase in compactness of the enzyme molecule which led to increase the intermolecular bonding (hydrogen bonding, van der waals and ionic forces). Furthermore, Saranya et al. [36] and Lee et al. [37] proposed that the increased intermolecular bonding and low molecular weight of the lipase can increase thermal and solvent resistance. Probably, the amino acid composition of PPL used in this research has hydrophobic characteristics. Thereby, this fact might give the tolerance feature exhibited to the lipase. Yet, there is a need for further molecular studies and additional tests.

The lowest amount of water $(2 \%)$ and the presence of an organic co-solvent in 1:1 oil/co-solvent ratio, increased FAME yield as compared to the treatment without cosolvent. In the parallel and final assays, the aqueous phase shows interactions with all the analyzed factors. We found the highest yields with $10 \%$ in parallel assay and 5\% in the final assay. This finding has been confirmed by other researchers. For example, Kaieda found in a methanolysis reaction catalyzed by a Pseudomonas cepacia lipase that reducing the water content facilitates FAME production, while, water in excess shifts the reaction equilibrium towards hydrolysis [17]. Moreover, when the lipase is non-resistant toward the solvent, it needs a minimum amount of water $[18$, $23,25]$. On the other hand, the low amount of water on the final product makes the process profitable as compared to alkali transesterification. Low water lipase catalysis eliminates the need for glycerol separation; avoid alkali traces, and additional process to eliminate water excess. High water amount accelerates the natural oxidation process and reduces the quality of the final product. Additionally, natural antioxidants of biodiesel such as tocopherols, sterols, and tocotrienols, are destroyed during distillation and purification steps in alkali catalyst reactions [38].

Co-solvent enhances the reaction kinetics due to solubilization of triacylglycerols and methanol in the reaction media forming reverse micelles. Therefore, inhibition by insolubilized methanol is avoided [39, 40]. PPL resistance to high methanol concentration and the activity in presence of hexane, indicate that the lipase retains its activity in organic solvents. According to Gaur et al. [15], this property is rare because organic solvents displace the water 
molecules needed for protein folding and occupy active sites. Thus, the lipase may lose its catalytic activity. It is also important to consider the free lipases aggregates formation in the presence of co-solvent because the mass transfer process is hindered. This condition could prevent the lipase activity [41].

In the final assay we identified a first order interaction between methanol-oil ratio/pH exhibiting a better FAME conversion at high stoichiometric ratios and $\mathrm{pH}$ 8. Murray et al. [42] revealed that $\mathrm{pH}$ is critical for protein folding and enzyme catalytic activity. In addition, $\mathrm{pH} 8$ was the best for the $P$. aeruginosa lipase, confirming previous research [15, $29,43]$. It is generally accepted that lipases need an specific $\mathrm{pH}$ range to conserve their appropriate folding, which will depend on its isoelectric point [42].

In the parallel assay it was observed that the reactor capacity affects the reaction yield. Smaller capacities facilitate interactions between the substrate, lipase and alcohol. The reaction yield has been tested in packed bed reactors [44-46], showing a higher efficiency when the reaction media has low flows through the stationary phase, increasing the contact between catalyst and reactants. Likewise, the enzyme amount influences the yield and the rate of the reaction, due to increased number of enzyme molecules able to react with the substrate $[18,22]$, as explained by Murray et al. [42].

Lipase purification positively affects the reaction yield. We carried out a partial purification process that must be improved further according the results. Other researches had reached lipase purification factors of approximately 300, improving their activity approximately 1000-fold compared to the enzyme supernatant $[15,28,47]$. Also, protein engineering is widely used to improve the lipase production yields and enzymatic activity $[48,49]$.

\section{CONCLUSION}

The partially purified lipase obtained from $P$. aeruginosa was isolated directly from palm oil fruit and it transesterified the palm oil triglycerides to FAME, making it suitable for biodiesel production. Each lipase requires individualized process conditions with appropriate control over them to improve the reaction yield. In this case, a partially purified lipase exhibited an improvement of the reaction yield compared to the lyophilized supernatant, producing more than $68 \%$ of FAME (34.68\% and $20.61 \%$ respectively). However, the lipase production and purification process yield must be improved due the protein losses on each step. Protein engineering is needed to improve the enzyme properties, making a profitable biocatalysis process for recommend it as a biocatalyst for oleochemical process and other industrial purposes.

\section{ABBREVIATIONS}

$$
\begin{aligned}
& \mathrm{CPO}=\text { Crude palm oil } \\
& \mathrm{GC}=\text { Gas chromatography } \\
& \text { LLS }=\text { Lyophilized lipase supernatant } \\
& \text { PPL }=\text { Partially purified lipase }
\end{aligned}
$$

$\mathrm{RBD}=$ Refined, bleached and deodorized

\section{CONFLICT OF INTEREST}

The authors confirm that this article content has no conflict of interest.

\section{ACKNOWLEDGEMENTS}

We appreciate the project funding and support from the Departamento Administrativo de Ciencia, Tecnología e Innovación COLCIENCIAS, and we are thankful to the Universidad de La Sabana for the project support and provided facilities.

\section{REFERENCES}

[1] UniProtKB/Swiss-Prot SI of B. ENZYME entry: EC 3.1.1.3. http://enzyme.expasy.org/EC/3.1.1.3.

[2] Gog, A.; Roman, M.; Toşa, M.; Paizs, C.; Irimie, F.D.; Tosa. M. Biodiesel production using enzymatic transesterification-Current state and perspectives. Renew. Energy, 2012, 39(1), 10-16.

[3] Christopher, L.; Kumar, H.; Zambare, V. Enzymatic biodiesel: Challenges and opportunities. Appl. Energy, 2014, 119, 497-520.

[4] Othman, R.; Mohammad, A.W.; Ismail, M.; Salimon, J. Application of polymeric solvent resistant nanofiltration membranes for biodiesel production. J. Membr. Sci., 2010, 348, 287-297.

[5] Shimada, Y.; Watanabe, Y.; Sugihara, A.; Tominaga, Y. Enzymatic alcoholysis for biodiesel fuel production and application of the reaction to oil processing. J. Mol. Catal. B: Enzym., 2002, 17 (3-5), 133-142.

[6] Abbaszaadeh, A.; Ghobadian, B.; Omidkhah, M.R. Current biodiesel production technologies: A comparative review. Energy Convers. Manag., 2012, 63, 138-148.

[7] Marchetti, J.M. A summary of the available technologies for biodiesel production based on a comparison of different feedstock's properties. Process Safety Environ. Prot., 2011, 90(3), 157-163

[8] Fukuda, I.; Kondo, A.; Noda, H. Biodiesel fuel production by tranesterification of oils. J. Biosci. Bioeng., 2001, 92(5), 405-416.

[9] Luković, N.; Knezevic-Jugovic, Z.; Bezbradica, D. Biodiesel fuel production by enzymatic transesterification of oils: recent trends, challenges and future perspectives. Alternative Fuel, In: Manzanera E., Ed.; InTech. 2011; Available from: http://cdn.intechopen.com/pdfs/17585/InTech-Biodiesel-fuelproduction-by-enzymatic-transesterification-of-oils-recent-trendschallenges-and-future-perspectives.pdf

[10] Jegannathan, K.L.; Eng-Seng, C.; Ravindra P. Economic assessment of biodiesel production: comparison of alkali and biocatalyst processes. Renew. Sust. Energy Rev., 2011, 15, 745751.

[11] Balat, M. Potential alternatives to edible oils for biodiesel production-A review of current work. Energy Convers. Manag., 2011, 52, 1479-1492.

[12] Rojas, A.F.; Girón, E.; Torres, H.G. Operation variables in transesterification of vegetable oil: an enzymatic catalysis review. Ing. Investig., 2010, 30, 17-21.

[13] Uscategui, Y.L.; Jimenez-Junca, C.; Suárez, C.; Prieto, R.E. Evaluation of the induction of lipolytic enzymes from Pseudomonas aeruginosa isolated from African palm fruit (Elaeis guineensis). VITAE-Colombia, 2012, 19(3), 280-285.

[14] Zor, T.; Selinger, Z. Linearization of the Bradford protein assay increases its sensitivity: theoretical and experimental studies. Anal. Biochem., 1996, 236, 302-308.

[15] Gaur, R.; Gupta, A.; Khare, S.K. Purification and characterization of lipase from solvent tolerant Pseudomonas aeruginosa PseA. Process Biochem., 2008, 43(10), 1040-1046.

[16] Gutiérrez, P.H.; De la Vara, R. Análisis y diseño de experimentos. Mc Graw Hill: USA, 2008.

[17] Kaieda, M.; Samukawa, T.; Kondo, A.; Fukuda, H. Effect of methanol and water contents on production of biodiesel fuel from plant oil catalyzed by various lipases in a solvent-free system. $J$. Biosci. Bioeng., 2001,91(1), 12-15. 
[18] Shah, S.; Gupta, M.N.; Sha, S. Lipase catalyzed preparation of biodiesel from Jatropha oil in a solvent free system. Process Biochem., 2007,42(3), 409-414.

[19] Gao, Y.; Chen, W.; Lei, H.; Liu, Y.; Lin, X. Optimization of transesterification conditions for the production of fatty acid methyl ester (FAME) from Chinese tallow kernel oil with surfactantcoated lipase. Biomas. Bioenerg., 2009, 33(2), 277-282.

[20] Rodrigues, R. Two step ethanolysis: A simple and efficient way to improve the enzymatic biodiesel synthesis catalyzed by an immobilized-stabilized lipase from Thermomyces lanuginosus. Process Biochem., 2010, 45(8), 1268-1273.

[21] Shieh, C-J.; Liao, H-F.; Lee, C-C.; Shie, C.J. Optimization of lipase-catalyzed biodiesel by response surface methodology. Bioresour. Technol., 2003, 88(2), 103-106.

[22] Sim, J.H.; Harun, A.; Bhatia, S. Effect of mass transfer and enzyme loading on the biodiesel yield and reaction rate in the enzymatic transesterification of crude palm oil. Energy Fuels, 2009, 23(9), 4651-4658.

[23] Atadashi, I.M.; Aroua, M.K.; Abdul Azis, A.R.; Sulaiman, N.M.N. The effects of water on biodiesel production and refining technologies: A review. Renew. Sustain. Energy Rev., 2012, 16(5), 3456-3470.

[24] Bisen, P.S.; Sanodiya, B.S.; Thakur, G.S.; Baghel, R.K.; Prasad G.B.K.S. Biodiesel production with special emphasis on lipasecatalyzed transesterification. Biotechnol. Lett., 2010, 32, 10191030 .

[25] Fjerbaek, L.; Chritensen, K.V.; Norddahl, B.; Christensen, K.V. A review of the current state of biodiesel production using enzymatic transesterification. Biotechnol. Bioeng., 2009, 102(5), 1298-1315.

[26] Akoh, C.C.; Chang, S-W.W.; Lee, G-C.C.; Shaw, J-F.F. Enzymatic approach to biodiesel production. J. Agric. Food Chem., 2007, 55 (22), 8995-9005.

[27] Braunschweig, T.U. Information on EC 3.1.1.3-triacylglycerol lipase, BRENDA 2013.

[28] Borkar, P.S.; Bodade, R.G.; Rao, S.R. Purification and characterization of extracellular lipase from a new strain Pseudomonas aeruginosa SRT 9. Braz. J. Microbiol., 2009, 40(2), 358-366.

[29] Sharma, R.; Chisti, Y.; Banarjee, U.C. Production, purification, characterization, and applications of lipases. Biotechnol. Adv., 2001, 19, 627-662.

[30] Talukder, M.M.R.; Wu, J.C.; Van Nguyen, T.B.; Fen, N.M.; Melissa, YLS. Novozym 435 for production of biodiesel from unrefined palm oil: Comparison of methanolysis methods. J. Mol. Catal. B. Enzym., 2009, 60, 106-112.

[31] Watanabe, Y.; Shimada, Y.; Sugihara, A.; Tominaga, Y. Conversion of degummed soybean oil to biodiesel fuel with immobilized Candida antarctica lipase. J. Mol. Catal. B. Enzym., 2002, 17(3-5), 151-155.

[32] Tan, T.; Lu, J.; Nie, K. Biodiesel production with immobilized lipase: A review. Biotechnol. Adv., 2010, 28(5), 628-634.

[33] Borugadda, V.B.; Goud, V.V. Biodiesel production from renewable feedstocks: Status and opportunities. Renew. Sustain. Energy Rev., 2012, 16, 4763-4784.

[34] Moreira, A.B.R.; Perez, V.H.; Zanin, G.M.; de Castro, H.F. Biodiesel synthesis by enzymatic transesterification of palm oil with ethanol using lipases from several sources immobilized on Silica-PVA composite. Energy Fuel, 2007, 21(6), 3689-3694.

[35] Stamenkovic, O.S.; Velickovic, A.V.; Veljkovic, V.B. The production of biodiesel from vegetable oils by ethanolysis: current state and perspectives. Fuel, 2011, 90, 3141-3155.

[36] Saranya, P.; Sukanya, K.H.; Prasad R.B.; Sekaran. G. Lipase production from a novel thermo-tolerant and extreme acidophile Bacillus pumilus using palm oil as the substrate and treatment of palm oil-containing wastewater. Environ. Sci. Pollut. Res. Int., 2014, 21(5), 3907-3919.

[37] Lee, D-W.; Koh, Y-S.; Kim, K-J.; Kim, B-C.; Choi, H-J.; Kim, DS.; Suharono M.T.; Pyun, Y-R. Isolation and characterization of a thermophilic lipase from Bacillus thermoleovorans ID-1. FEMS Microbiol. Lett., 1999, 179, 393-400.

[38] Sharma, Y.C.; Singh, B.; Upadhyay, S.N. Advancements in development and characterization of biodiesel: A review. Fuel 2008, 87, 2355-2373.

[39] Stamatis, H.; Xenakis, F.N. Bioorganic reactions in microemulsions: the case of lipases. Biotechnol. Adv., 1999, 17(45), 293-318.

[40] Antczak, S.M.; Kubiak, A.; Antczak, T.; Bielecki, S. Enzymatic biodiesel synthesis-Key factors affecting efficiency of the process. Renew. Energy, 2009, 34(5), 1185-1194.

[41] Triantafyllou, A.O.; Wehtje, E.; Adlercreutz, P.; Mattiasson, B. How do additives effect enzyme activity and stability in nonaqueous media? Biotechnol. Bioeng., 1997, 54(1), 67-76.

[42] Murray, R.K.; Kenelly, Peter J.; Bender, David A.; Rodwell, Victor W., Botham, Kathleen M. HARPER. Bioquimica ilustrada. McGraw Hill, USA, 2010.

[43] Chartrain, M.; Katz, L.; Marcin, C. Purification and characterization of a novel bioconverting lipase from Pseudomonas aeruginosa MB 5001. Enzym. Microbiol. Technol., 1993, 15(7), 575-580.

[44] Hama, S.; Tamalampudi, S.; Yoshida, A.; Tamadani, N.; Kuratani, N. Enzymatic packed-bed reactor integrated with glycerolseparating system for solvent-free production of biodiesel fuel. Biochem. Eng. J., 2011, 55(1), 66-71.

[45] Yoshida, A.; Hama, S.; Tamadani, N.; Fukuda, H.; Kondo, A. Improved performance of a packed-bed reactor for biodiesel production through whole-cell biocatalysis employing a highlipase-expression system. Biochem. Eng. J., 2012, 63, 76-80.

[46] Chen, H-C.; Ju, H-Y.; Wu, T-T.; Liu, Y-C.; Lee, C-C.; Chang, C. Continuous production of lipase-catalyzed biodiesel in a packedbed reactor: optimization and enzyme reuse study. J. Biomed. Biotechnol., 2011, 2011, 1- 6.

[47] Saeed, H.; Zaghloul, T.I.; Khalil, A.I.; Abdelbaeth, M.T. Purification and characterization of two extracellular lipases from Pseudomonas aeruginosa Ps-x. Pol. J. Microbiol., 2005, 54(3), 233-40.

[48] Ogino, H.; Inouea, S.; Yasudaa, M.; Doukyub, N. Hyper-activation of foldase-dependent lipase with lipase-specific foldase. $J$. Biotechnol., 2013, 166(1-2), 20-24.

[49] Bora, L.; Gohain, D.; Das, R. Recent advances in production and biotechnological applications of thermostable and alkaline bacterial lipases. J. Chem. Tec hnol. Biotechnol., 2013, 88(11), 1959-1970. 